\title{
A CONSTRUÇÃO DA CIDADE, A URBANIDADE E O PATRIMÔNIO AMBIENTAL URBANO: \\ O CASO DO BEXIGA, SÃO PAULO
}

NADIA SOMEKH UNIVERSIDADE PRESBITERIANA MACKENZIE, SÃO PAULO, SÃO PAULO, BRASIL Doutora em Arquitetura e urbanismo.Professora titular do Programa de Pós-Graduação em Arquitetura e Urbanismo da Universidade Presbiteriana Mackenzie,São Paulo, SP, Brasil. E-mail: nadiasom@terra.com.br

DOI

http://dx.doi.org/10.11606/issn.1980-4466.v0i22p220-241 


\section{A CONSTRUÇÃO DA CIDADE, A URBANIDADE E O PATRIMÔNIO AMBIENTAL URBANO: O CASO DO BEXIGA, SÃO PAULO \\ NADIA SOMEKH}

\section{RESUMO}

A chamada globalização e a reestruturação produtiva se caracterizam pelo esvaziamento dos espaços industriais, portos, orlas ferroviárias e centros históricos, pelas novas tecnologias que conectam o mundo, pelo divórcio de política e poder, bem como pela dissolução de vínculos. A obsolescência produzida pelo capitalismo faz com que haja a necessidade de regeneração de tecidos urbanos bem localizados, muitas vezes de forma "espontânea", ou seja, conduzida pelos desígnios do mercado, sem projeto. A noção de urbanidade deve abrigar, dentro do espectro da sustentabilidade, o desenvolvimento local, sua relação com o tecido social e a possibilidade do encontro na esfera pública. O desenvolvimento local, enquanto prioridade nas políticas urbanas, pode ser compreendido de diversas maneiras. De um lado, liga-se à esfera econômica, sendo medido pela evolução do quadro produtivo local, pela geração de emprego e renda no seio das comunidades, pelo acréscimo da autonomia fiscal dos governos locais e pela diversificação/ dinamização de atividades econômicas, com impacto na integração das populações marginalizadas. Em termos sociais, liga-se à busca da inclusão de diferentes setores populares, em um quadro de crescimento e evolução econômica. Combatem-se os efeitos excludentes da nova ordem mundial com linhas de ação, programas e projetos que tirem proveito das especificidades e potencialidades de cada região, partindo dos interesses da população. Entendemos também que a proteção do patrimônio deve ser tratada dentro da questão ambiental urbana. A apropriação dos espaços públicos produz urbanidade; a participação e o diálogo na identificação e proteção do patrimônio constrói o futuro das cidades. Dentro desse quadro, como produzir urbanidade? Quais os instrumentos contemporâneos de regulação urbana? Como então formular uma política de preservação do patrimônio cultural levando em conta o desenvolvimento sustentável? Como construir cidade a partir do patrimônio? A proposta é o debate de uma agenda que retome o conceito de patrimônio ambiental urbano. A verticalização, a 
multiplicação do solo urbano, aumentando densidades e colocando mais pessoas usufruindo boas localizações urbanas, pode ser realizada de maneira a incluir urbanidade. Como definir cidade compacta? Como definir urbanidade? No caso de São Paulo, como os instrumentos previstos no novo plano diretor podem incluir a produção de espaços públicos e Preservação efetiva do seu patrimônio cultural? Utilizando-se do bairro do Bexiga, o presente artigo, organizado em três partes, levanta questionamentos acerca dessas questões: a política da preservação, a renovação de bairros históricos, terminando com a proposta de novas agendas para a preservação.

\section{PALAVRAS-CHAVE}

Patrimônio Cultural. Renovação urbana. Política urbana. 


\section{BULDING THE CITY, URBANITY AND URBAN ENVIRONMENTAL HERITAGE: THE CASE OF BIXIGA, SÃO PAULO. \\ NADIA SOMEKH}

\section{ABSTRACT}

The so-called globalization and/or productive restructuration produces obsolesced and abandoned ports, industrial neighborhoods, railway margins and historical city centers. It happens due to factors such as new technologies of communication, the divorce between politics and power, as well as to weakened bonds and structures. The obsolescence produced by capitalism generates the need for regenerating well located urban fabrics, although quite often in a "spontaneous" way, that is, driven solely by the market, without mediation of a project. To be sustainable, the notion of urbanity must encompass the local development, its links to the social fabric and the possibility for encounters and exchanges among people in the public space. Local development, as a priority in new urban policies, may be understood in several ways. It connects to the economic dimension, being then measured by the accumulated local built environment, by jobs and income creation, by increased fiscal autonomy of local administrations and by diversification and improvement of economic activities which integrate marginalized populations. In social terms, it is linked to the inclusion of different cultural and social groups. It is possible to face the excluding effects of the new world order with programs and projects which make the most of each region's specificities, starting from local populations demands. Cultural heritage must be dealt with as an urban environment matter. People's appropriation of the public space produces urbanity; participation in identifying and protecting cultural heritage contributes in constructing the future of cities. How can we promote urbanity in this new context? What are the contemporary urban regulation instruments? How to formulate a sustainable cultural heritage protection policy? How to build the city from its heritage as a departing point? The proposal is to reestablish an agenda that brings the concept of Urban Environmental Heritage back to the front line.

The verticalization, an act of multiplying urban land, increases density, placing a larger amount of inhabitants enjoying advantageous urban locations 
can be done including urbanity. How to define a compact city? How to define urbanity? In the case of São Paulo, how do the instruments of the city's new masterplan can enable the production of public spaces and the effective preservation of cultural heritage? Using the Bixiga neighborhood as a case study, this article raises questions regarding preservation policies and redeveloping historic neighborhoods, and proposes a new agenda for cultural preservation.

\section{KEYWORDS}

Cultural Heritage. Urban renewal. Urban policy. 


\section{INTRODUÇÃO}

As cidades brasileiras vêm sendo produzidas com um modelo urbano carente de urbanidade. O binômio demolição/construção resultou em um processo de verticalização que vem destruindo o patrimônio na cidade. As transformações recentes da indústria e a reestruturação produtiva trouxeram para as nossas cidades a convivência de velhos e novos problemas. Essa reestruturação deixou vazias áreas bem equipadas, ampliando o processo de expansão e consequente dilapidação dos recursos naturais. Por outro lado, desigualdades sociais persistem principalmente na questão habitacional.

Sob a luz do desenvolvimento urbano sustentável, as cidades contemporâneas vêm passando por transformações que podem ser elencadas apontando a necessidade de ampliar a importância da proteção do patrimônio cultural, bem como dos espaços públicos, garantindo a permanência da identidade e democracia urbana. Nesse sentido, entendemos que repensar a construção da cidade significa atacar velhos e novos problemas: ampliar a oferta habitacional de diversas faixas de renda, reduzindo a gentrificação; (re)estabelecer uma mobilidade que atenda às demandas da transformação climática; produzir espaços públicos de qualidade e preservar o patrimônio histórico, reforçando núcleos identitários para cidadãos globalizados.

Em síntese, podemos apontar como principal processo contemporâneo, que influencia diretamente na produção da cidade, a chamada globalização 
e/ou reestruturação produtiva, que esvazia espaços industriais, portos, orlas ferroviárias e centros históricos, a novas tecnologias conectando o mundo, o divórcio de política e poder e a dissolução de vínculos. A obsolescência, intrínseca ao sistema capitalista, traz a necessidade de regeneração de tecidos urbanos bem localizados muitas vezes de forma espontânea, ou seja, sem a mediação de um projeto. Entendemos também que a proteção do patrimônio deve ser tratada dentro da questão urbana. Nos anos 1970, em São Paulo, o patrimônio histórico foi tratado pelo órgão de Planejamento, entretanto, ao longo da sua atuação, foi se fragmentando e se desarticulando da questão urbana. Dentro desse quadro, como então formular uma política de preservação do patrimônio cultural levando em conta o desenvolvimento sustentável? Como construir cidade a partir do patrimônio?

As transformações funcionais mencionadas demandam novas formas de proteção do patrimônio cultural e histórico. Como ocorre a materialização do espaço urbano e como ele é apropriado? Como conferir qualidade e inclusão? O conceito de cidade compacta é defendido por Rogers e foi estabelecido no Programa de Desenvolvimento Educacional 2014 (PDE), de São Paulo. Consiste em concentrar população otimizando os investimentos realizados e reduzindo o avanço da cidade sobre zonas com recursos naturais a serem preservados. O limite da cidade compacta é a urbanidade, aqui entendida como possibilidade de boa convivência através de espaços públicos democráticos e pré-existências norteadoras de memória e identidade. A cidade compacta requer um sistema de transporte compatível e inclusivo. $\mathrm{O}$ automóvel não contribui para a constituição de uma cidade compacta. A promoção da cidade compacta pode reduzir a dilapidação dos recursos naturais e promover a redução do uso do automóvel.

O que debateremos neste trabalho é a utilização do conceito "patrimônio ambiental urbano" como elemento de construção de uma cidade compacta com urbanidade.

Estruturamos o trabalho em três partes: a primeira estabelece o debate conceitual de perspectivas de constituição da problemática de uma política de preservação, a segunda levanta questões acerca do bairro do Bexiga e suas perspectivas de desenvolvimento na contemporaneidade e, a partir dessa reflexão, na terceira parte, apresentamos alguns avanços e uma agenda para posturas de preservação. 


\section{O CONCEITO DE PATRIMÔNIO AMBIENTAL URBANO}

Meu primeiro encontro com o conceito de patrimônio ambiental urbano foi a partir do curso realizado na Faculdade de Arquitetura e Urbanismo da Universidade de São Paulo (FAU-USP) em 1978 com o mesmo nome. Para Meneses, "Patrimônio ambiental urbano é um sistema de objetos, socialmente apropriados, percebidos como capazes de alimentar representações de um ambiente urbano" (MENEZES, 1978). A sua seleção é determinada pela sua carga de significação dotada de potencial legitimador, integrador e, portanto, transformador. É necessário ampliar a significação social. O projeto de futuro de uma cidade deve incorporar "o código de interação que efetivamente organiza as relações sociais daqueles objetos que fornecem ingredientes para as imagens da cidade” (Ibidem). Para Yázigi (2001), o patrimônio ambiental urbano é constituído de conjuntos arquitetônicos urbanísticos e demais elementos urbanos tendo a inclusão social como exigência crescente. Para o autor, o conceito está em constante transformação e "deve se configurar como o ser e o porvir". Retoma a assertiva de Cervelati (1978): a preservação do patrimônio ambiental não pode existir fora da preservação social.

A ideia de monumento e conceito de patrimônio tout court é uma ideia construída pela Organização das Nações Unidas para a Educação, a Ciência e a Cultura (Unesco) que deve ser superada e transformada em "herança" daquilo que buscamos transmitir às gerações futuras (BIASE, 2014). A superação do conceito de monumento para edifícios e conjuntos de importância histórica ocorre com a carta de Veneza, de 1964, incorporada no Brasil pela criação do Conselho de Defesa do Patrimônio Histórico, Arqueológico, Artístico e Turístico (Condephaat), em 1968. A Declaração de Amsterdã, de 1975, propõe a conservação e reabilitação de núcleos urbanos articulados e integrados ao processo de planejamento urbano. Esses dois documentos têm como projeto ícone a cidade de Bolonha, que ainda coloca a participação e a inclusão social no cerne do seu conceito de preservação. A carta de Nairobi, de 1976, aponta recomendações para a preservação contemporânea de áreas históricas, apontando a limitação da musealização do patrimônio edificado:

O documento ainda define ambiente como cenário, seja natural ou criado pelo homem, que influencia a maneira pela qual as áreas históricas 
são percebidas ou são ligadas espacialmente por fatores sociais, econômicos e culturais. As áreas históricas, objeto do documento, devem ser consideradas como uma totalidade coerente, em que o equilíbrio depende da inter-relação dos componentes principais, as atividades humanas, os edifícios, a organização espacial e os arredores. (LUSTOZA, 2011)

Dentro desse quadro não se poderia entender a preservação do patrimônio ambiental urbano fora do planejamento das cidades. Não foi o que se observou no Brasil em São Paulo. Bonduki (2012) aponta como um dos problemas do balanço da experiência do Banco Interamericano de Desenvolvimento (BID) no Brasil, o programa Monumenta, a desarticulação dos projetos com a política urbana. Meneses vai além dessa perspectiva integradora: propõe que o Ministério ou as Secretarias de Cultura deveriam se responsabilizar não só pela administração de instituições de eventos "culturais, mas sobretudo, na identificação da dimensão cultural em todas as políticas públicas de um governo" (MENEZES, 1978).

No caso de São Paulo, a ação municipal de preservação teve sua origem em 1974, na Coordenadoria Geral de Planejamento (COGEP), entidade instalada originalmente no Gabinete do Prefeito, com a elaboração da lista de bens culturais a serem protegidos solicitados aos professores Benedito Lima de Toledo e Carlos Lemos, posteriormente incorporada ao zoneamento a partir da definição das zonas especiais Z8-200 (SOMEKH, 2015). A criação do Departamento do Patrimônio Histórico (DPH) e do Conselho Municipal de Preservação do Patrimônio Histórico, Cultural e Ambiental da Cidade de São Paulo (Conpresp) representou uma fragmentação nesse processo de revisão urbanística que agora começa a ser retomada.

Tentativas de integração ocorreram antes da constituição do conselho quando da instituição do Inventário Geral de Patrimônio Ambiental Urbano (Igepac) que buscava incorporação do conceito de patrimônio ambiental urbano desenvolvido a partir do curso da FAU, das experiências de Bolonha e recomendações das Cartas Patrimoniais.

Uma avaliação crítica a respeito dos instrumentos de preservação no nível municipal, bem como de uma revisão histórica dessas ações aponta a necessidade de busca de instrumentos financeiros complementares à identificação e ao tombamento para efetivar a proteção dos bens preservados. 
Entendemos que projetos urbanos podem trazer recursos para a preservação do patrimônio ambiental urbano desde que sejam constituídos coletivamente. Para isso, elegemos os trabalhos que apontaram caminhos nessa direção.

\section{O BEXIGA}

Dentro da perspectiva de trabalhar os temas da verticalização e produtividade urbana, urbanidade e patrimônio cultural, o bairro do Bexiga se apresenta como um dos mais relevantes para a discussão dos padrões de materialização da cidade de São Paulo atualmente.

Trata-se de um bairro tradicional e central, que data do início da expansão da cidade, ainda no período colonial, representando um tecido social riquíssimo - tendo sido parada de escravos fugidos, local de assentamento dos primeiros imigrantes italianos e hoje abrigando importante parte da comunidade nordestina recém-chegada à cidade.

As características de sua ocupação e constante ressignificação fazem com que hoje o bairro abrigue um considerável número de agentes e produtores culturais e artísticos, festas populares e inúmeras apropriações interessantes dos seus espaços públicos.

Suas diferentes fases de desenvolvimento e transformação representam momentos importantes do desenvolvimento de São Paulo. O bairro já recebeu inúmeros projetos de renovação e revitalização. Se, por um lado, passou por fases de transformação intensa e verticalização, com o espraiamento de processos de desenvolvimento do centro e da região da Avenida Paulista, por outro permaneceu ainda com grande parte de suas edificações e patrimônio cultural intactos, graças ao processo iniciado em 1990 que culminou na resolução de tombamento pelo Conpresp em 2002.

O Bexiga não pode ser considerado hoje um bairro imobilizado dado o tombamento - mas em constantes transformações - dadas as suas dinâmicas de desenvolvimento e o acúmulo de projetos para ele elaborados.

Com as mudanças e oportunidades introduzidas pelo Novo Plano Diretor (PDE-2014), o bairro se apresenta como um interessante ponto de partida para a discussão das possíveis relações entre verticalização e densidade - estimuladas nos eixos de adensamento - e urbanidade - aqui definida como a construção das relações entre o patrimônio cultural, os espaços públicos, a diversidade de usos e o tecido social existente. 


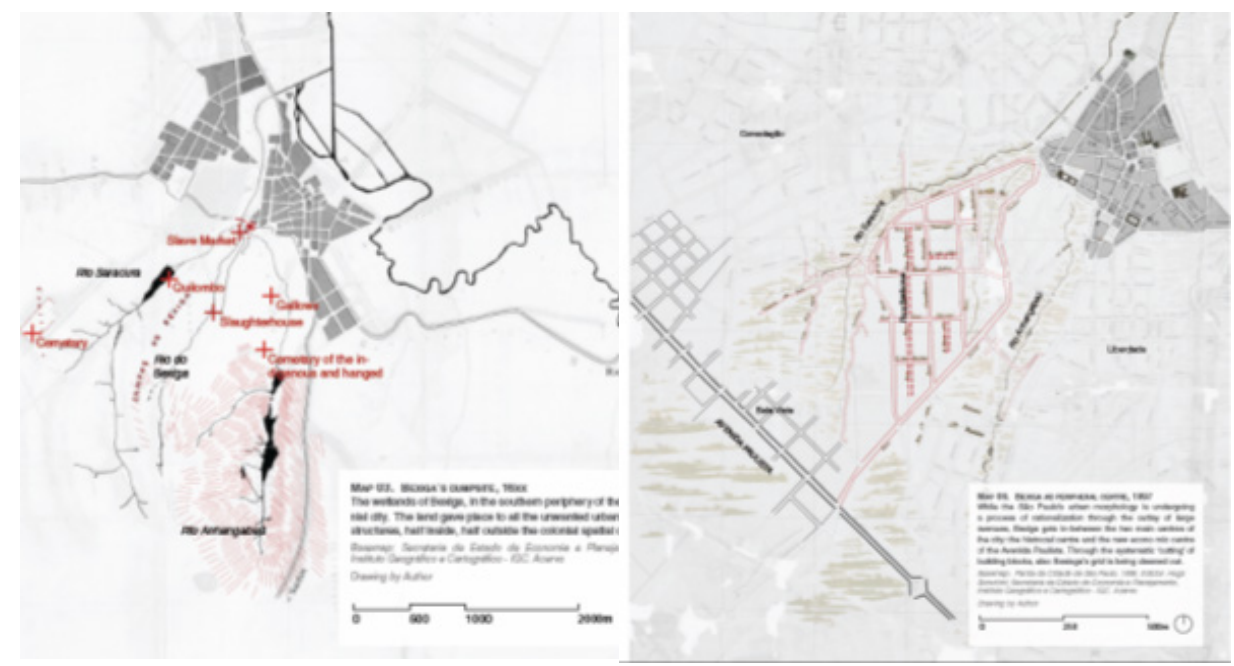

As experiências acadêmicas (GIANOTTO, 2015; STEVENS, 2013) nos mostram a complexidade até mesmo de definição do que é o bairro do Bexiga, dados os diversos perímetros de abrangência político-administrativa e simbólica a que o bairro remete. Para efeitos desta análise, trabalhamos com o perímetro considerado o mais adequado ao momento fundacional do bairro e suas profundas relações com o sítio em que se insere, abrangendo a área entre os rios Itororó e Saracura e o espigão da Avenida Paulista.

3.1 Verticalização e produtividade urbana: a questão da densidade. Ao tratar da questão da verticalização e do desenvolvimento urbano do Bexiga, podemos aliá-la à noção de produtividade urbana e às discussões sobre cidade compacta.

A pesquisa sobre o crescimento vertical de São Paulo é uma tarefa difícil e complexa, entretanto, podemos oferecer um panorama geral do processo, quantificá-lo e apontar seus principais problemas. A verticalização em si não é um problema e sim a forma que vem assumindo em São Paulo: a cidade foi perdendo o seu projeto de urbanidade e é necessário resgatá-lo. A experiência dos nossos trabalhos nos mostrou que São Paulo é uma cidade vertical, mas não é densa. Essa afirmação pode também ser feita sobre a verticalização do Bexiga? 
A periodização adotada para o crescimento vertical não só segue os grandes períodos do desenvolvimento econômico, mas também os movimentos políticos no Brasil, através da ação do Estado, de maneira geral, e especificamente em relação ao urbano. Esses dois critérios - o desenvolvimento da economia e a ação do Estado - somados a um terceiro específico, que se refere à caracterização do fenômeno estudado e suas variações quantitativas e qualitativas, nortearam a definição dos períodos e a sua descrição. Assim, definimos os seguintes períodos de verticalização (SOMEKH, 1978):

- de 1920 a 1940: a verticalização europeia, período em que edifícios altos seguem padrões europeus de construção;

- de 1940 a 1957: a verticalização americana, de características ascendentes, que começa com a implantação do registro de elevadores e vai até a primeira limitação do coeficiente de aproveitamento dos terrenos. O padrão de construção valorizado passa a ser o norte-americano;

- de 1957 a 1967: a verticalização do automóvel, período de estagnação ou crescimento moderado, quando a ênfase do crescimento industrial está voltada para outros setores, como o automobilístico, sendo que o automóvel define um novo tipo de ocupação;

- de 1967 a 1972: a verticalização do milagre, período de ascensão vertiginosa que apresenta um índice de crescimento vertical bastante significativo, tendo início com as ações do Banco Nacional de Habitações (BNH) na promoção do desenvolvimento imobiliário;

- de 1972 a 1988: a verticalização pós-zoneamento, começando depois da promulgação da legislação de zoneamento, passando pela desaceleração econômica da década perdida, o fim do BNH em 1986, até a Constituição de 1988 e do PD 88 permitindo as Operações Urbanas e Interligadas, que possibilitaram um aumento dos coeficientes de aproveitamento;

- de 1988 a 2004: a verticalização negociada, a reversão da "desverticalização" anterior, com o aumento de coeficientes proporcionado pelas Operações Urbanas e Interligadas, aliadas à constituição dos fundos de pensão, produziu novos eixos do setor terciário avançado, tais como as avenidas Brigadeiro Faria Lima, Luís Carlos Berrini, Juscelino Kubitscheck e a Marginal do rio Pinheiros; 
- de 2004 até 2011: a verticalização metropolitana, a guerra de coeficientes da Região Metropolitana de São Paulo (RMSP), aliada a preços fundiários mais baixos, atraiu o crescimento vertical para cidades vizinhas ou para outras centralidades mais distantes, como Alphaville, ampliando os deslocamentos pendulares e agravando ainda mais o trânsito de São Paulo.

Exemplos desses períodos podem ser encontrados pelo perímetro do bairro estudado, configurando diversos padrões de densidade e definindo diferentes padrões de urbanidade, através da inserção urbana do edifício vertical e de suas relações com o tecido urbano tradicional do bairro.

Ressaltamos que o crescimento vertical em São Paulo pode ser dividido em duas partes, a primeira até 1988, que denominamos de Desverticalização; a outra, de 1988 até hoje, quando ocorreu a reversão da redução dos coeficientes de aproveitamento, por meio das Operações Urbanas e da Outorga Onerosa. Entretanto, o processo de reversão recente não se apresenta como suficiente para produzir uma cidade compacta e evitar um transbordamento metropolitano da verticalização. Qual foi a forma urbana resultante e qual é a relação com as grandes transformações viárias do bairro? A análise do processo de desenvolvimento urbano e verticalização na cidade em geral demonstra que a materialização do espaço ocorre pela regulação e pelos desígnios do capital sem a busca efetiva de urbanidade. Dentro desse quadro, interessa conhecer melhor o impacto da verticalização em bairros tradicionais e sua relação com as densidades existentes.

As recentes mudanças na política urbana da cidade de São Paulo, a partir da aprovação do novo PDE (2014), configuram-se uma ousada tentativa de reestruturação da cidade através de instrumentos urbanísticos com foco em dez estratégias: (1) Socialização dos ganhos da produção da cidade; (2) Melhora da mobilidade urbana; (3) Orientação do crescimento; (4) Promoção do desenvolvimento econômico; (5) Preservação do patrimônio e estímulo à cultura; (6) Implantação de política habitacional; (7) Qualificação da vida urbana nos bairros; (8) Reorganização das dinâmicas metropolitanas; (9) Incorporação da agenda ambiental; (10) Fortalecimento da participação popular.

Com o objetivo de reequilibrar a cidade, grande foco foi colocado na questão do acesso à terra urbana - uma das questões críticas em São Paulo 
— bem como nas funções e densidades ideais para cada região e eixo, através do sistema de tipologias incentivadas, incentivos ao uso misto, controle da forma urbana, aumento significativo da área destinada aos empreendimentos de habitação social e o estabelecimento da cota de solidariedade, que prevê que o desenvolvimento imobiliário no mercado da habitação venha acompanhado da realização também de habitação de interesse social. Além da mobilidade, destacam-se as diretrizes para as áreas verdes, parques e praças. O plano prevê instrumentos de incentivo à promoção de áreas verdes em terrenos privados e a preservação do patrimônio cultural, mediante a transferência do direito de construir e os incentivos para a proliferação de espaços de fruição pública no térreo de novos empreendimentos, com o objetivo de aumentar os espaços de uso público disponíveis da zona consolidada.

$\mathrm{Na}$ busca de uma cidade compacta com uma mobilidade eficiente e menos consumidora de recursos naturais, o patrimônio histórico poderá ser preservado dentro de uma perspectiva contemporânea e valorizadora da identidade paulistana com a criação de novos instrumentos, como as Zonas Especiais de Preservação Cultural - ZEPECs APC - e os Territórios Culturais e Criativos.

Essas inovações foram também propostas para o contexto do Bexiga, como podemos ver nos mapas abaixo:

FIGURA 2

Mapas da infraestrutura modal e suas

zonas de influência

e instrumentos urbanísticos incidentes no Bexiga de acordo com o PDE 2014

Fonte: São Paulo (cidade), 2014

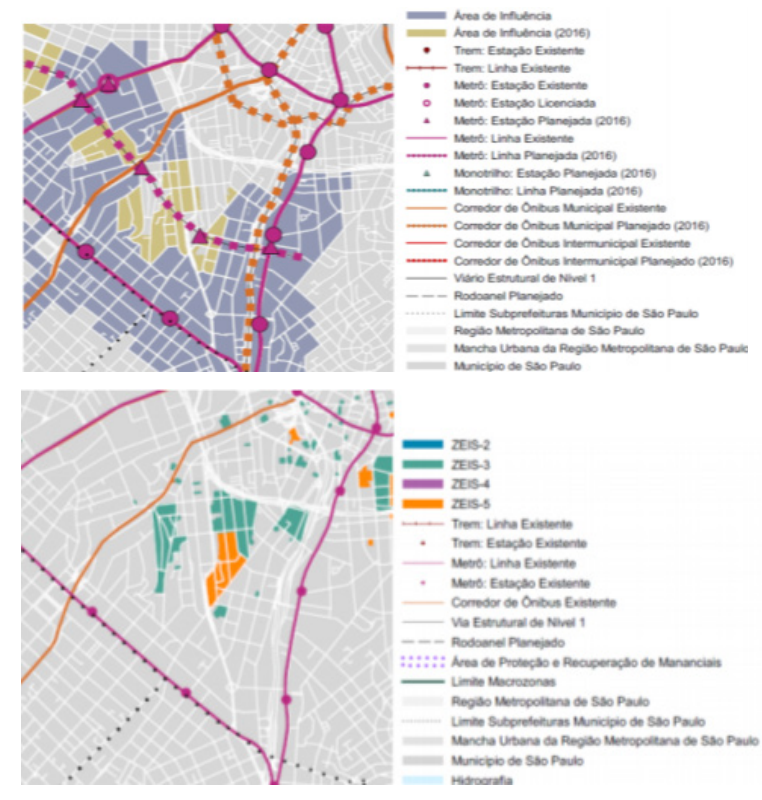


A partir desse novo marco regulatório, perguntamo-nos: Quais transformações podemos esperar a partir da nova regulação? Qual é a sua relação com as noções de produtividade urbana e de urbanidade?

\subsection{Patrimônio cultural: a preservação do patrimônio no Bexiga.}

As primeiras ações acerca da preservação do patrimônio cultural no Bexiga aconteceram na sequência do concurso Parque da Grota, em 1974. O projeto vencedor, de Paulo Mendes da Rocha, propunha a demolição de grande parte do patrimônio construído na área da Grota do Bexiga, por ser considerado de pouco valor cultural e histórico. Essa proposta levantou a necessidade de conhecer e reconhecer o patrimônio cultural de um dos bairros mais tradicionais da cidade, culminando no processo de inventário realizado pelo então recém-criado (1975) Departamento do Patrimônio Histórico (DPH), responsável por inventariar e proteger os bens culturais paulistanos. Para entender esse processo e em que medida ele se insere em uma política de preservação mais ampla do patrimônio, recorremos a um breve histórico das políticas de preservação do município.

Apesar da existência do DPH desde 1975, o tombamento no âmbito municipal não foi possível até a criação do Conpresp, em 1985. Os primeiros tombamentos foram realizados três anos depois: o Casarão à Rua Brigadeiro Luiz Antônio, n. 42, localizado no Bexiga, e o Estádio Municipal Paulo Machado de Carvalho, o Pacaembu. Até então o órgão de patrimônio recorria ao Condephaat ou Iphan para promover a salvaguarda dos bens considerados de extrema importância.

A Carta de Veneza, documento do International Council of Monuments And Sites (Icomos), de maio de 1964, amplia a noção de monumento histórico, estendendo-a não só a grandes criações, mas também a "obras modestas que tenham adquirido significação cultural” (ICOMOS, 1964). Segundo Kühl (2010), o curso da FAU-USP, sobre restauração e conservação de monumentos arquitetônicos, ocorrido em 1974 em parceria com o Iphan e o Condephaat, possibilitou um debate consistente sobre o documento e pode ter referenciado a demanda municipal de proteção de conjuntos urbanos. A partir dessa mudança de paradigma, então internalizada pelo órgão municipal de patrimônio, passam se a realizar inventários aliados ao processo de tombamento, levando em consideração características além do bem a ser tombado. 
A Divisão de Preservação do DPH foi constituída em 1977 a partir de então os inventários foram estruturadores do trabalho da preservação no último quarto do século XX. À luz de um momento singular para a preservação, tanto na cidade de São Paulo como no Brasil, o Inventário Geral do Patrimônio Ambiental (Igepac) foi gestado e teve sua metodologia estabelecida entre os anos de 1982 e 1983, continuando a operar até 2003. O Igepac foi um modelo que buscava ir além da preservação pontual do bem e procurava identificar as características urbanas que constituíam o patrimônio ambiental e cultural de cada bairro, registrá-las e elaborar propostas de preservação (BAFFI, 2006). Nesse contexto foi produzido o Igepac Bela Vista, finalizado em 1984. O trabalho tratou de levantar os edifícios mais significativos do ponto de vista histórico-arquitetônico, reconhecer os elementos urbanos caracterizadores locais, identificando conjuntos urbanos, além de levantar elementos construtivos, edificações e estruturas de valor ambiental, bem como componentes urbanos geomorfológicos como escadarias, muros de arrimo, encostas e coberturas vegetais existentes no bairro.

Pouco tempo após a realização do Igepac Bela Vista, foi lançado o Concurso Nacional de Ideias para a Renovação Urbana e Preservação do Bexiga (1989 -1990), uma iniciativa da Empresa Municipal de Urbanização (Emurb) que contou com ampla participação popular e envolvimento dos atores locais, mobilizando o tecido social ali existente.

Em oposição à experiência de concurso realizada para o perímetro da Grota, as premissas do concurso indicavam a necessidade de compatibilizar processos de transformação e preservação no bairro, o engajamento e manutenção da população moradora e o mínimo de intervenção no tecido urbano possível.

O concurso de ideias, apesar de não executado, gerou grande mobilização local e o resultado desse trabalho embasou o processo de tombamento, cujo pedido partiu de iniciativa popular em 1990, culminando na resolução Conpresp-Resolução 11/90, alterada pela Resolução o1/93. Inicialmente a Resolução n. 11/9o abrangia 1400 imóveis e englobava toda a Bela Vista. Posteriormente, a resolução de 1993 definiu manchas especiais de preservação. 
FIGURA 3

Estudo de intervenção em miolo de quadra realizado por

uma das equipes escolhidas. Fonte: GIANOTTO, 2015

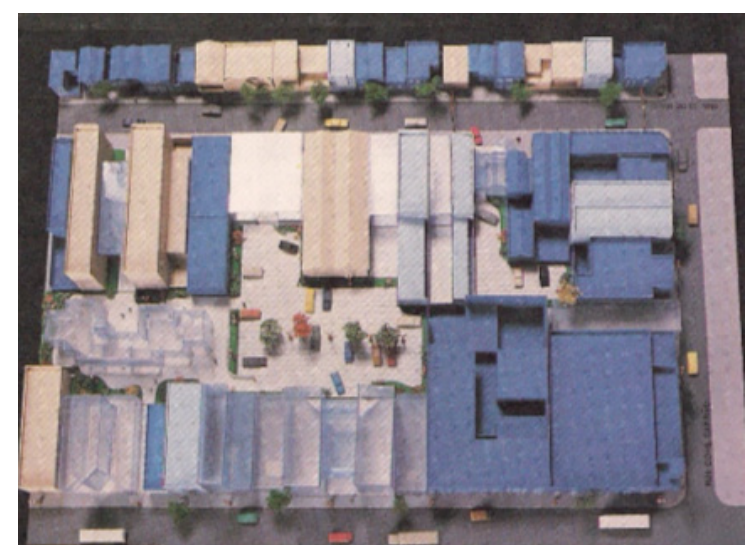

FIGURA 4

Proposta de calçadão na Rua Treze de Maio realizado por uma das equipes escolhidas. Fonte: GIANOTTO, 2015.

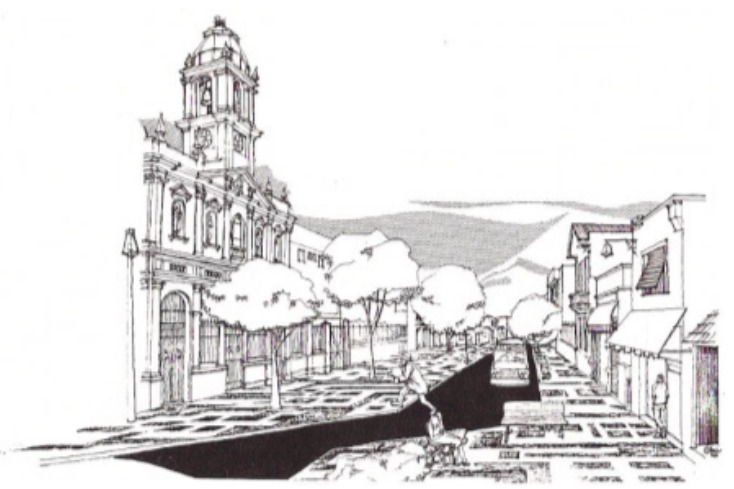

FIGURA5

Mapa do plano de conservação do Bairro. Fonte: São Paulo (cidade). Resolução 1-93 - Bela Vista Conpresp, 1993.

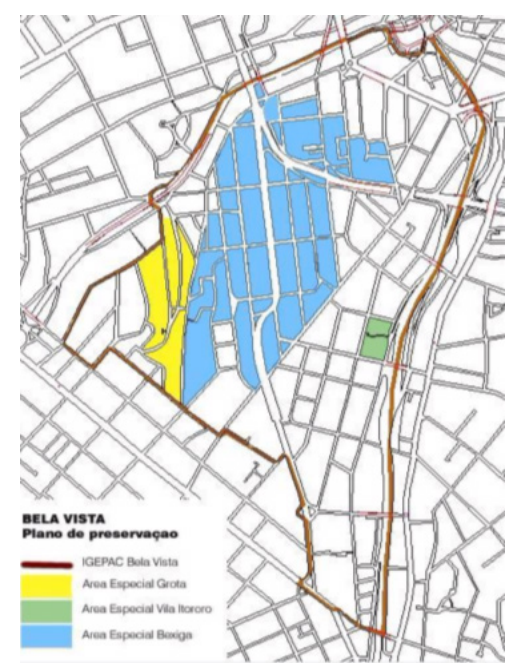


Foi proposta a preservação do traçado viário, de bens imóveis significativos e elementos relevantes levantados no inventário.

O tombamento ocorreu pela Resolução 22-2002 do Conpresp, tendo como base uma atualização do Igepac de 1984, realizada em 2001, somando diferentes níveis de preservação para 569 imóveis no Bexiga; 80 imóveis na Grota; a Vila Itororó, com 36 elementos; além de 217 imóveis isolados.

A política de preservação, entretanto, encerrou-se com o tombamento. Como ocorreu a relação entre preservação do patrimônio e desenvolvimento urbano no contexto do Bexiga? A elaboração do Plano Diretor de 2002 e os subsequentes Planos Regionais e Lei de Uso e Ocupação do Solo (LUOS), em 2004, simplificaram o zoneamento da cidade e transformaram as antigas Z8-20o em ZEPECs - Zonas Especiais de Patrimônio Cultural. As ZEPECs, entretanto, não expandiram o conceito de proteção do patrimônio cultural para além dos elementos tombados, não integrando a criação de projetos mais abrangentes para a preservação da esfera urbana do patrimônio cultural e de sua vinculação com outras diretrizes de política urbana além da LUOS.
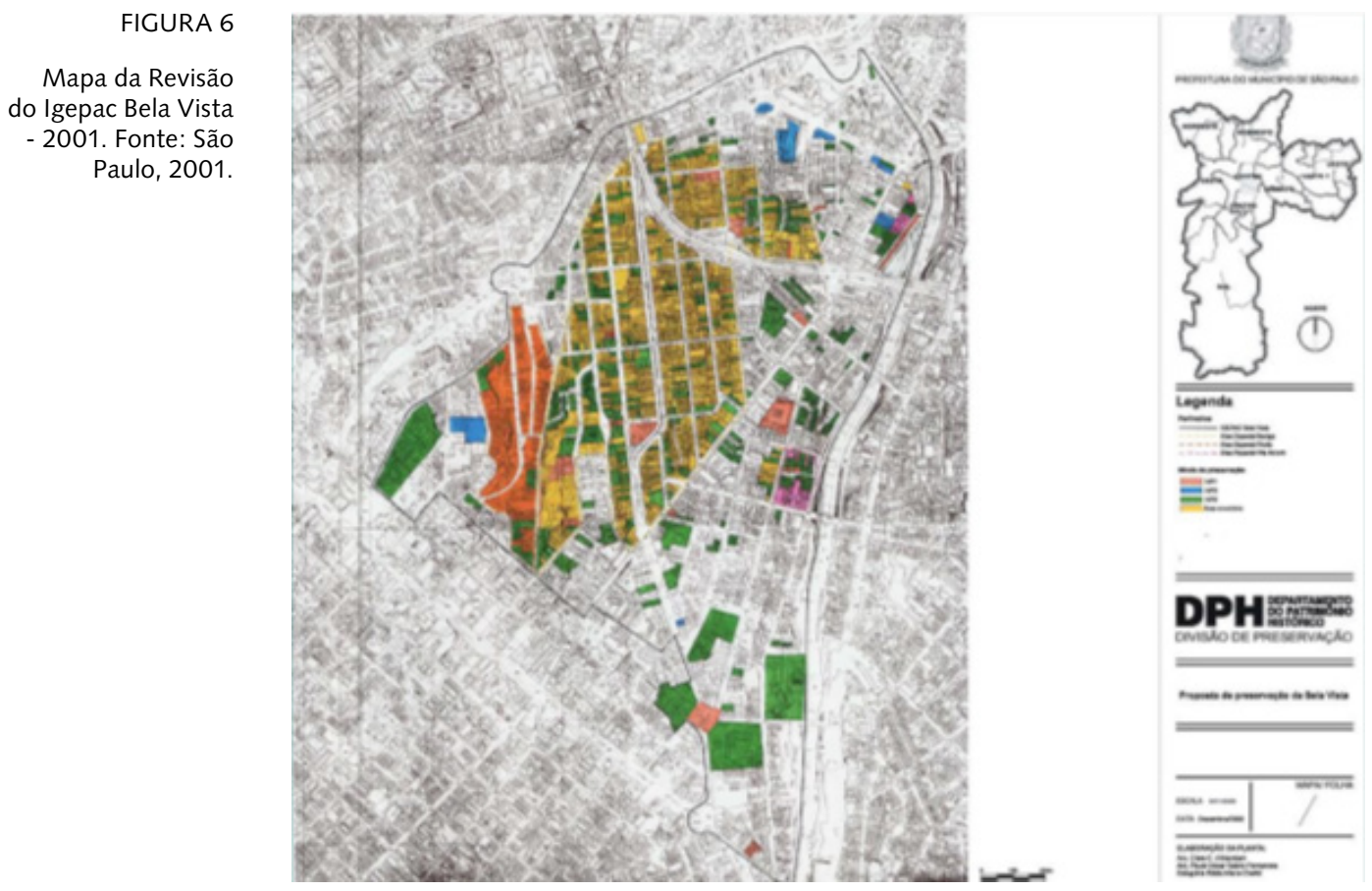
O desenvolvimento local aliado à preservação do patrimônio ainda carece de instrumentalização. Como captar recursos através da produção de cidade, além da outorga onerosa, para a valorização da memória coletiva em busca de um futuro de melhor qualidade urbana?

O novo PDE de 2014 trouxe como conceito a produção da cidade compacta. Como poderá incluir efetivamente o patrimônio cultural como elemento de urbanidade diante dos desafios da contemporaneidade? $\mathrm{O}$ DPH, ao longo de sua existência, utilizou o tombamento como principal instrumento, desvinculou-se de planos urbanos utilizando apenas a definição de gabaritos como principal instrumento de valorização, e ainda não avançou nem na captação de recursos, nem no estímulo aos proprietários para a recuperação do seu patrimônio. Quais são os instrumentos de captação de recursos e valorização que poderiam ser aliados à política atual de preservação do patrimônio cultural?

\section{POR UMA AGENDA DO PATRIMÔNIO AMBIENTAL URBANO.}

A cidade contemporânea se caracteriza pelo resultado das transformações tecnológicas da reestruturação produtiva e da dissolução de vínculos identitários. Espaços produtivos esvaziados vêm passando por projetos urbanos que nem sempre, principalmente no Brasil, dão conta das preexistências históricas. O desperdício e a obsolescência criados pelo capitalismo tardio se traduzem em experiências voltadas para a produção de empreendimentos imobiliários a partir de tábula rasa, de forma ambientalmente insustentável.

O patrimônio é uma questão urbana, contudo vem sendo tratado como mero projeto de resistência, sem a busca efetiva para protegê-lo e conservá-lo. Projetos urbanos podem proteger o patrimônio e o ambiente desde que tratados com participação e inclusão social, desde que construídos socialmente. Ampliar a participação, a disseminação do conhecimento, da sensibilização ao patrimônio pode conduzir à construção de projetos urbanos com inclusão social. Para Poltosi (2016), a legislação recente das cidades brasileiras tem conduzido a fragmentação da paisagem urbana e que o patrimônio ambiental urbano é uma base para o desenvolvimento da cidade não um obstáculo. A análise da inserção o patrimônio ambiental urbano no quadro regulatório, normas e leis, planos e projetos é essencial para a busca de uma ação mais efetiva. A partir da experiência internacional propõe a desfragmentação da 
gestão pública na criação de revalorização do patrimônio ambiental urbano. Ao tratar da valorização do patrimônio, percebemos alguns avanços recentes em São Paulo, dos quais destacamos a criação e regularização da Jornada do Patrimônio, do Selo de Valor Cultural Paulistano e a iniciativa Fábrica de Restauro, que propôs a promoção da coesão social em áreas com grande incidência de imóveis tombados na cidade.

No caso da Jornada, sua primeira edição, em 2015, contou com mais de 400 atividades de memória concentradas em um final de semana de dezembro. Cerca de 40 mil cidadãos puderam fazer visitas guiadas em imóveis históricos, acompanhar roteiros de memória, assistir palestras, participar de oficinas e ver apresentações artísticas ligadas ao nosso patrimônio imaterial. A segunda edição, em agosto de 2016, foi novamente um sucesso de público e consolidou o evento. Transformada em lei em outubro de 2016, a Jornada do Patrimônio passa a fazer parte do calendário oficial de atividades da gestão pública, garantindo a continuidade dessa importante ação de valorização do patrimônio. Outra ação inovadora para a visibilidade do patrimônio foi a criação do selo Valor Cultural Paulistano. Ao reconhecer estabelecimentos tradicionais da cidade e imóveis importantes para segmentos específicos da população, o selo ofereceu ao cidadão uma ferramenta para lutar pela preservação de seus bens, conduzindo à maior participação popular.

Além de ações de visibilidade, a valorização do patrimônio presume o apoio da sociedade civil, bem como articulação com atores locais, proprietários, usuários e entidades preocupadas com a Preservação. Sendo assim, o DPH criou o piloto do projeto Fábrica de Restauro, envolvendo o território da Vila Maria Zélia e do Bexiga, com o objetivo de estimular a gestão compartilhada e o cooperativismo de pequenos proprietários de bens tombados privados e outras esferas da sociedade civil.

No caso da Bela Vista, bairro tombado na cidade de São Paulo abordado por Gianotto (2015), apresenta fatores de estagnação advinda de planos e projetos fragmentados. A esperança apontada consiste na implantação do metrô sem a desarticulação de espaços de convivência popular. Há, contudo um longo caminho a percorrer, pois a sociedade que não conhece não valoriza. Portanto, engajar os cidadãos no reconhecimento e valorização de sua história nos conduz à necessidade de programas de sensibilização. Ampliar 
participação, ampliar a disseminação do conhecimento, da sensibilização ao patrimônio pode conduzir a projetos urbanos com inclusão social.

\section{REFERÊNCIAS}

BAFFI, Mirthes. O Igepac-SP e outros inventários da Divisão de Preservação do DPH: um balanço. Revista do Arquivo Histórico Municipal, São Paulo, v. 204, p.169-191, 2006.

BIASE, Alessia de. Hériter de La Ville. Paris: Donner Lieu, 2014.

BONDUKI, Nabil. Intervenções urbanas na recuperação de centros históricos. Brasília: Iphan, 2012.

COMITÊ DE MINISTROS DO CONSELHO DA EUROPA. Manifesto de Amsterdã. Amsterdã, 1975

GERALDES, E. A. S. Paisagem, identidade e memória: Vila Picinguaba. 2001. Dissertação (Mestrado em Geografia Humana). Faculdade de Filosofia, Letras e Ciências Humanas, Universidade de São Paulo, São Paulo. 2001.

GIANNOTTO, Joice Chimati. Fedora e o Bixiga: projetos e planos para o bairro paulistano. 2014. 155 f. Dissertação (Mestrado em Arquitetura e Urbanismo). Universidade Presbiteriana Mackenzie, São Paulo, 2015.

INTERNATIONAL COUNCIL OF MONUMENTS AND SITES. Carta de Veneza. Veneza, Itália: Icomos, 1964.

Carta de Burra. Burra, Austrália: Icomos, 1980.

LUSTOZA, Regina. E. Patrimônio ambiental urbano: revendo conceitos. Artigo apresentado no $9^{\circ}$ Seminário Docomomo Brasil - interdisciplinaridade, experiências em documentação e preservação do patrimônio recente, Brasília, 2011.

MENESES, Ulpiano T. Bezerra de. Patrimônio ambiental urbano: do lugar comum ao lugar de todos. CJ Arquitetura, v. 5, p. 18-20, 1978.

MORI, Victor Hugo; SOUZA, Marise Campos de; BASTOS, Rossano Lopes; Gallo, Haroldo (Orgs.). Patrimônio: atualizando o debate. São Paulo: Iphan, 2006.

ORGANIZAÇÃO DAS NAÇÕES UNIDAS PARA A EDUCAÇÃO, A CIÊNCIA E A CULTURA. Proteção do patrimônio mundial, cultural e natural. Paris: ONU, 1967.

ORGANIZAÇÃO DAS NAÇÕES UNIDAS PARA O MEIO AMBIENTE. Declaração de Estocolmo. Estocolomo, Suécia: ONU, 1972.

. Recomendação Paris paisagens e sítios. Paris: ONU, 1962.

POLTOSI, R. Patrimônio Ambiental Urbano e Revitalização Urbana: estratégias possíveis para $\mathrm{O} 4^{\circ}$ distrito. Artigo apresentado para o IV Encontro da Associação Nacional de Pesquisa e Pós-Graduação em Arquitetura e Urbanismo. Porto Alegre, 2016.

ROGERS, Richard. Cidades para um pequeno planeta. Londres: Gustavo Gili, 1997. 
SANTOS, Milton. A natureza do espaço. São Paulo: Edusp, 1966.

SÃO PAULO (Cidade). Secretaria Municipal de Cultura. Departamento do Patrimônio Histórico. Igepac Bela Vista (relatório). São Paulo, 2001.

SÃO PAULO (Cidade). Secretaria Municipal de Cultura. Departamento do Patrimônio Histórico. Conselho Municipal de Preservação do Patrimônio Histórico. Resolução 1-1993. São Paulo, 1993. Disponível em: < http://www.prefeitura.sp.gov.br/cidade/upload/1aeb7_o1_APT_ Bairro_Bela_Vista.pdf $>$. Acesso em: out 2015.

SÃO PAULO (Cidade). Secretaria Municipal de Cultura. Departamento do Patrimônio Histórico. Conselho Municipal de Preservação do Patrimônio Histórico. Resolução 22-2002. São Paulo, 2002. Disponível em: < http://www.prefeitura.sp.gov.br/cidade/upload/49c99_22_T_ Bairro_da_Bela_Vista.pdf $>$. Acesso em: out. 2015.

SOMEKH, N. A (des)verticalização de São Paulo. 1987. (Mestrado em Arquitetura e Urbanismo). Faculdade de Arquitetura e Urbanismo, Universidade de São Paulo, São Paulo, 1987.

SOMEKH, Nadia. Patrimônio cultural em São Paulo: resgate do contemporâneo? Arquitextos, São Paulo, ano 16, n. 185.08. Disponível em: <http://www.vitruvius.com.br/revistas/read/arquitextos/16.185/5795>. Acesso em: out. 2015.

VARINE-BOHAM, H. A experiência internacional: notas de aula. São Paulo: FAU/USP, 1974.

YÁZIGI, Eduardo. Patrimônio ambiental urbano: refazendo um conceito para o planejamento urbano. Artigo apresentado no Simpósio de Geografia Urbana da Universidade de São Paulo, 2001.

Artigo recebido em: 17/20/2016

Artigo aprovado em: 01/12/2016 